\title{
MicroRNA-125b targeted STAT3 to inhibit laryngeal squamous cell carcinoma cell growth and motility
}

\author{
JUAN FENG, YUQIN FAN, QUKUERHAN AYIHENG, HUA ZHANG, JUN YONG and BIN HU \\ Department of Otorhinolaryngology, The First Affiliated Hospital of Xinjiang Medical University, \\ Urumqi, Xinjiang Uyghur 830054, P.R. China
}

Received July 28, 2015; Accepted March 3, 2017

DOI: $10.3892 / \mathrm{ol} .2017 .6155$

\begin{abstract}
A majority of studies have indicated that microRNA-125b (miR-125b) is aberrantly expressed in various types of cancer. However, there are no studies on the expression and function of miR-125b in human laryngeal squamous cell carcinoma (LSCC). In the present study, miR-125b expression in LSCC sample tissues, corresponding adjacent non-neoplastic tissues, LSCC cell lines and a normal human keratinocyte cell line was measured using the reverse transcription-quantitative polymerase chain reaction. Following transfection with miR-125b mimics, the Cell Counting Kit-8, cell migration, cell invasion, western blotting and dual-luciferase reporter assays were performed on LSCC cell lines. According to the results, miR-125b was observed to be significantly downregulated in LSCC, and its expression was significantly associated with clinical stage and alcohol history. miR-125b was also observed to decrease cell growth, migration and invasion in LSCC cells by directly targeting signal transducer and activator of transcription 3 . The results of the present study suggested that miR-125b may be a potential treatment target of LSCC in the future.
\end{abstract}

\section{Introduction}

Laryngeal carcinoma, the second most common type of head and neck malignancy, accounts for $\sim 2.4 \%$ of all newly diagnosed malignant tumors (1). In the United States, it is estimated that there will be 13,360 new cases of laryngeal carcinoma and 3,660 associated mortalities in 2017. Among these estimated new cases and mortalities, males account for $79.12 \%$ of the new cases and $80.33 \%$ of the mortalities (2). This is primarily due to tobacco and alcohol abuse, and results in substantial

Correspondence to: Professor Jun Yong, Department of Otorhinolaryngology, The First Affiliated Hospital of Xinjiang Medical University, 137 South Liyushan Road, Urumqi, Xinjiang Uyghur 830054, P.R. China

E-mail: Dr_junyong@163.com

Key words: laryngeal squamous cell carcinoma, microRNA-125b, targeted therapy, signal transducer and activator of transcription 3 annual morbidity and mortality (3). Laryngeal squamous cell carcinoma (LSCC), the most common subtype of laryngeal carcinoma, accounts for $>95 \%$ of laryngeal carcinoma cases (4). Currently, the primary therapeutic strategy for LSCC is surgical intervention or total laryngectomy, followed by radiation therapy and chemotherapy (5). These treatments have a favorable curative effect on early-stage patients; however, are associated with a poor prognosis in more advanced-stage cases (6). Despite improvements in the diagnosis and treatment of LSCC, the 5-year survival rate has not significantly increased in the past 20 years (7). Therefore, an improved understanding of the molecular mechanisms of LSCC carcinogenesis and progression is essential in the development of novel diagnostic and therapeutic targets for patients with LSCC.

MicroRNAs (miRNAs) have been demonstrated to be a novel method of gene regulation mechanism (8). miRNAs are a large family of small (22-25 nucleotides in length) non-protein-coding, endogenous and single-stranded RNAs, which regulate post-transcriptional gene expression through association with the 3'-untranslated region (UTR) of target mRNAs, resulting in mRNA degradation or translational inhibition $(9,10)$. Currently, $>30 \%$ of human protein-coding genes are considered to be accommodated by miRNAs (11). Increasing evidence suggested that miRNAs serve a critical role in a number of physiological and pathological processes, including cell growth, development, differentiation, apoptosis, survival, migration and invasion $(12,13)$. The abnormal expression of miRNAs is hypothesized to be involved in various types of human cancer, including human LSCC (14-16). Dysregulated miRNAs may function as tumor suppressors or oncogenes, in the carcinogenesis and development of various types of human cancer (17). These results suggested that miRNAs may be a novel target for LSCC therapy.

A majority of studies have indicated that miRNA-125b (miR-125b) is aberrantly expressed in various types of cancer (18-20). However, to the best of our knowledge, there are currently no studies on miR-125b in LSCC. In the present study, the expression and function of miR-125b in LSCC was investigated. The results of the present study demonstrated that miR-125b was markedly downregulated in LSCC tissues and cell lines. The statistical analysis also indicated that the expression level of miR-125b was significantly associated with clinical stage and alcohol history in patients with LSCC. Upregulation of miR-125b decreased cell growth, migration 
and invasion by directly targeting signal transducer and activator of transcription 3 (STAT3). These results suggested that miR-125b may be investigated for further therapy in patients with LSCC.

\section{Materials and methods}

Clinical specimens. Tissue samples, LSCC tissues and their corresponding adjacent non-neoplastic tissues, were obtained from 52 patients with LSCC undergoing surgery resection at The First Affiliated Hospital of Xinjiang Medical University (Urumqi, China). Patient clinical features are presented in Table I. All patients had not received other therapies, including radiotherapy and chemotherapy, prior to surgery. Tissue samples were immediately preserved in liquid nitrogen following excision from patients and subsequently transferred to a $-80^{\circ} \mathrm{C}$ refrigerator until use. The present study was approved by the Human Research Ethics Committee of The First Affiliated Hospital of Xinjiang Medical University. Written informed consent was obtained from all patients used in the present study, as well as their clinicopathological features.

Cell culture. The LSCC cell line (AMC-HN-8) and a normal human keratinocyte cell line (HaCaT) were obtained from Shanghai Institute of Biochemistry and Cell Biology (Shanghai, China). Cells were maintained in Dulbecco's modified Eagle's medium (DMEM) supplemented with $10 \%$ (v/v) fetal bovine serum (FBS), and 1\% (v/v) penicillin/streptomycin (all Gibco; Thermo Fisher Scientific, Inc., Waltham, MA, USA), at $37^{\circ} \mathrm{C}$ in a humidified atmosphere containing $5 \% \mathrm{CO}_{2}$.

Transfection.AMC-HN-8 cells were transfected with miR-125b mimics and negative control(NC) miRNA, or cotransfected with luciferase reporter plasmid [pGL3-STAT3-3'UTR-wild-type (Wt) or pGL3-STAT3-3'UTR-mutated (Mut)] using Lipofectamine 2000 (Invitrogen; Thermo Fisher Scientific, Inc.), according to the manufacturer's protocol. The sequence of the miR-125b mimic was 5'-UCCCUGAGACCCUAA CUUGUGA-3'. The sequence of the NC mimic was 5'-UUC UCC GAA CGU GUC ACG UTT-3'. MicroRNA mimics and luciferase report plasmid were synthesized and obtained from Shanghai GenePharma Company (Shanghai, China).

RNA isolation and reverse transcription-quantitative polymerase chain reaction ( $R T-q P C R)$ analysis. Total RNA was isolated from LSCC tissues, adjacent non-neoplastic tissues and cells using Trizol reagent (Invitrogen; Thermo Fisher Scientific, Inc.), according to the manufacturer's protocol. Reverse transcription was performed using the Moloney Murine Leukemia Virus Reverse Transcription system (Promega Corporation, Madison, WI, USA). qPCR was subsequently performed using SYBR $^{\circledR}$ Premix Ex Taq ${ }^{\text {TM }}$ II (Takara, China) and the ABI 7300 Real-Time PCR detection system, according to the manufacturer's protocol. The thermocycling conditions for qPCR was as follows: 5 min at $95^{\circ} \mathrm{C}$; followed by 40 cycles of $95^{\circ} \mathrm{C}$ for $30 \mathrm{sec}$ and $65^{\circ} \mathrm{C}$ for $45 \mathrm{sec}$. The primer sequences used for qPCR were: $\mathrm{miR}-125 \mathrm{~b}$ forward, 5'-GCUCCCUGAGACCCUAAC-3' and reverse, 5'-CAGTGC AGGGTCCGAGGT-3'; U6 forward, 5'-CGCTTCGGCAGC
ACATATACTA-3' and reverse, 5'-GCGAGCACAGAATTA ATACGAC-3'; STAT3 forward, 5'-CCCATACCTGAAGAC CAAGTTTATC-3' and reverse, 5'-TGGAAATAATGGTGA AGGTGCTG-3'; GAPDH forward, 5'-TGCACCACCAAC TGCTTA-3' and reverse, 5'-GGATGCAGGGATGATGTT C-3'. Results were quantified using the $2^{-\Delta \Delta C q}$ method (21).

Cell Counting Kit-8 (CCK8) assay. The role of miR-125b on LSCC cell proliferation was evaluated using the CCK8 assay (Dojindo Molecular Technologies, Inc., Kumamoto, Japan). A total of $24 \mathrm{~h}$ following transfection, 3000 AMC-HN-8 cells were added into each well of 96-well plates in triplicate. At various times $(24,48,72$ and $96 \mathrm{~h})$ following treatment, the CCK8 assay was performed. A total of $10 \mu \mathrm{l}$ CCK8 solution was added into each well and incubated for $2 \mathrm{~h}$ at $37^{\circ} \mathrm{C}$. The optical density at $450 \mathrm{~nm}$ for each well was measured using an ELISA reader (Bio-Rad Laboratories, Inc., Hercules, CA, USA). The suppression rate was calculated using the following formula: Suppression rate $=\left(1-\mathrm{OD}_{\mathrm{miR}-125 \mathrm{~b}} / \mathrm{OD}_{\mathrm{NC}}\right) \times 100$. Each experiment was performed at least three times.

Migration and invasion assay. The function of miR-125b in cell motility was measured using Transwell chambers (Costar; Corning Incorporated, Corning, NY, USA) with $8-\mu \mathrm{m}$ pore polycarbonate membranes. A total of $48 \mathrm{~h}$ following transfection, $3 \times 10^{4}$ AMC-HN-8 cells in $200 \mu \mathrm{l}$ DMEM without FBS were added into the upper chamber of the Transwell chamber in a 24-well plate. In the lower chamber, $500 \mu 1$ DMEM containing $20 \%$ FBS was used as a chemoattractant. The Transwell chamber was precoated with Matrigel (BD Biosciences, San Jose, CA) for the invasion assay and without Matrigel for the migration assay. Cells were incubated at $37^{\circ} \mathrm{C}$ for $24 \mathrm{~h}$. The chambers were subsequently fixed with $100 \%$ methanol for $10 \mathrm{~min}$ and stained with $0.1 \%$ crystal violet for $5 \mathrm{~min}$ at room temperature. Cells that did not migrate or invade through the membrane were removed using a cotton swab. The membranes were subsequently viewed under an inverted microscope and images were captured (magnification, x200). All the experiments were performed in triplicate.

Bioinformatic analysis. The potential targets of miR-125b were analyzed using miRanda (http://www.microrna.org) and TargetScan (http://www.targetscan.org/).

Western blot analysis. A total of $72 \mathrm{~h}$ following transfection, cells were lysed in cold radioimmunoprecipitation assay buffer (Beyotime Institute of Biotechnology, Haimen, China) containing protease and phosphatase inhibitors. Bicinchoninic Acid Assay kit (Beyotime Institute of Biotechnology) was used to determine the protein concentrations. Equal amounts of protein were subjected to SDS-PAGE and subsequently transferred to polyvinylidene difluoride membranes (EMD Millipore, Billerica, MA, USA). The membranes were blocked with $5 \%$ non-fat milk at room temperature for $2 \mathrm{~h}$, and subsequently incubated with primary antibodies against STAT3 (1:1,000 dilution; catalog: \#9139; Cell Signaling Technology, Inc., Danvers, MA, USA) and $\beta$-actin (1:1,000 dilution; sc-130065; Santa Cruz Biotechnology, Inc., Dallas, TX, USA) at $4^{\circ} \mathrm{C}$ overnight. Membranes were washed with TBS containing $0.1 \%$ Tween-20 and incubated with the corresponding horseradish peroxidase-conjugated secondary antibody $(1: 5,000$ 
Table I. Association between the expression of miRNA-125b and clinicopathological factors in patients with laryngeal squamous cell carcinoma.

\begin{tabular}{|c|c|c|c|c|}
\hline \multirow{2}{*}{$\begin{array}{l}\text { Clinical } \\
\text { features }\end{array}$} & \multirow{2}{*}{$\begin{array}{c}\text { Case } \\
\text { number }\end{array}$} & \multicolumn{2}{|c|}{$\begin{array}{l}\text { Relative } \\
\text { miR-125b } \\
\text { expression }\end{array}$} & \multirow[b]{2}{*}{ P-value } \\
\hline & & High & Low & \\
\hline Sex & & & & 0.697 \\
\hline Male & 45 & 16 & 29 & \\
\hline Female & 7 & 3 & 4 & \\
\hline Age, years & & & & 0.559 \\
\hline$<60$ & 21 & 9 & 12 & \\
\hline$\geq 65$ & 31 & 10 & 21 & \\
\hline Smoking history & & & & 0.510 \\
\hline Negative & 13 & 6 & 7 & \\
\hline Positive & 39 & 13 & 26 & \\
\hline Alcohol history & & & & $0.010^{\mathrm{a}}$ \\
\hline Negative & 23 & 13 & 10 & \\
\hline Positive & 29 & 6 & 23 & \\
\hline T stage & & & & 0.389 \\
\hline $\mathrm{T} 0 / 1 / 2$ & 25 & 11 & 14 & \\
\hline $\mathrm{T} 3 / 4$ & 27 & 8 & 19 & \\
\hline $\mathrm{N}$ stage & & & & 1.000 \\
\hline Negative & 34 & 12 & 22 & \\
\hline Positive & 18 & 7 & 11 & \\
\hline M stage & & & & 0.247 \\
\hline Negative & 29 & 13 & 16 & \\
\hline Positive & 23 & 6 & 17 & \\
\hline Clinical stage & & & & $0.043^{\mathrm{b}}$ \\
\hline Low (I-II) & 25 & 13 & 12 & \\
\hline High (III-IV) & 27 & 6 & 21 & \\
\hline
\end{tabular}

${ }^{\mathrm{a}} \mathrm{P}<0.05$ negative alcohol history vs. positive alcohol history in patients with low miR-125b expression. ${ }^{b} \mathrm{P}<0.05$ low clinical stage vs. high clinical stage in patients with low miR-125b expression. miR, microRNA; T, tumor; $\mathrm{N}$, node; $\mathrm{M}$, metastasis.

dilution; sc-2005; Santa Cruz Biotechnology, Inc.) for $2 \mathrm{~h}$ at room temperature. The bound antibodies were visualized using an enhanced chemiluminescence kit (GE Healthcare Life Sciences, Chalfont, UK) and analyzed using Quantity One software (Bio-Rad Laboratories, Inc.).

Dual-luciferase reporter assay. The human LSCC cells, plated in a 24 -well plate at $70 \%$ confluence, were transfected with miR-125b mimics, NC and cotransfected with luciferase reporter plasmids (pGL3-STAT3-3'UTR-Wt or pGL3-STAT3-3'UTR-Mut) using Lipofectamine 2000. A total of $48 \mathrm{~h}$ following transfection, Renilla and firefly luciferase activities were measured using the Dual-Luciferase Reporter assay system (Promega Corporation), according to the manufacturer's protocol. Renilla luciferase activity was used as a control. Each sample was assayed in triplicate.
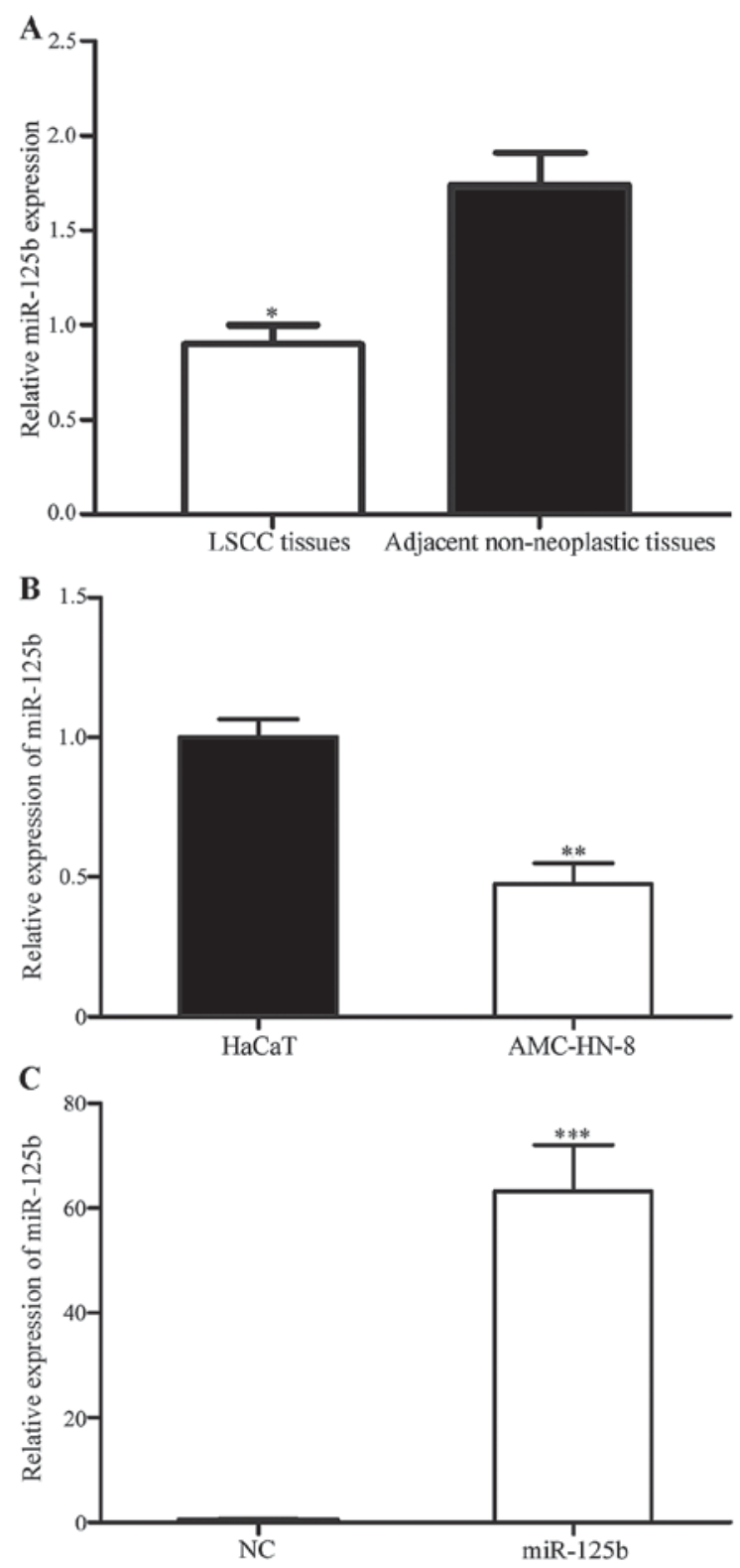

Figure 1. Expression of miR-125b in LSCC sample tissues and cell lines (A) miR-125b was downregulated in LSCC tissues compared with their corresponding adjacent non-neoplastic tissues. "P<0.0 vs. the adjacent non-neoplastic tissues. (B) miR-125b was downregulated in AMC-HN-8 cells compared with the HaCaT cell line. ${ }^{* *} \mathrm{P}<0.05$ vs. HaCaT cells. (C) miR-125b was upregulated in AMC-HN-8 cells transfected with miR-125b mimics compared with cells transfected with the $\mathrm{NC} .{ }^{* * *} \mathrm{P}<0.05$ vs. the $\mathrm{NC}$-transfected cells. LSCC, laryngeal squamous cell carcinoma; NC, negative control.

Statistical analysis. Data were presented as the mean \pm standard deviation and compared using two-tailed Student's t-test or one-way analysis of variance using SPSS software (version 17.0; SPSS, Inc., Chicago, IL, USA). The SNK method was applied to compare between two groups in multiple groups. $\mathrm{P}<0.05$ was considered to indicate a statistically significant difference.

\section{Results}

miR-125b expression is downregulated in LSCC. The expression of miR-125b in 52 paired LSCC tissues and corresponding adjacent non-neoplastic tissues was studied using quantitative RT-PCR. As presented in Fig. 1A, miR-125b was significantly 

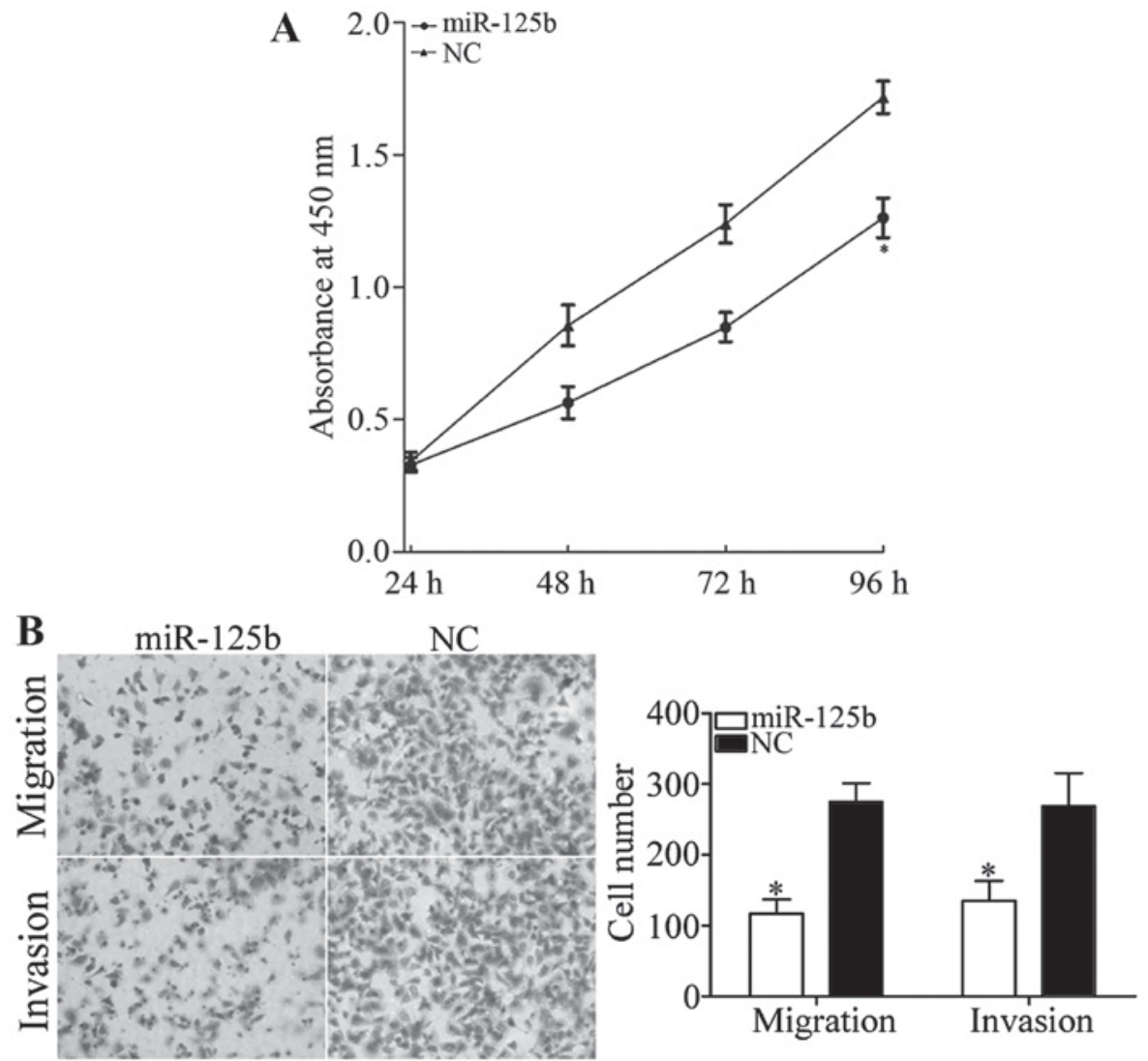

Figure 2. miR-125b inhibits cell growth, migration and invasion in AMC-HN-8 cells. (A) The Cell Counting kit-8 assay demonstrated that miR-125b decreased cell growth in AMC-HN-8 cells. (B) Upregulation of miR- $125 \mathrm{~b}$ inhibited the migratory and invasive ability of AMC-HN-8 cells (magnification, $\mathrm{x} 200$ ). ${ }^{*} \mathrm{P}<0.05$ vs. the NC-transfected cells. miR, microRNA; NC, negative control.

downregulated in LSCC tissues compared with the corresponding adjacent non-neoplastic tissues $(\mathrm{P}<0.05)$. In addition, the expression level of miR-125b in an LSCC and normal human keratinocyte cell line was detected. As presented in Fig. 1B, miR-125b was also significantly downregulated in AMC-HN-8 cells compared with HaCaT cells $(\mathrm{P}<0.05)$. These results indicated that miR-125b may serve important roles in LSCC.

To investigate the roles of miR-125b in LSCC cells, miR-125b mimics were transfected into AMC-HN-8 cells using Lipofectamine 2000. To assess the transfection efficiency, RT-qPCR was performed following transfection. As presented in Fig. 1C, miR-125b was significantly upregulated in cells transfected with miR-125b mimics compared with cells transfected with the $\mathrm{NC}(\mathrm{P}<0.05)$.

Association between miR-125b expression and clinicopathological features of patients with LSCC. To investigate whether miR-125b expression was associated with the clinicopathological features of patients with LSCC, statistical analysis was used. As presented in Table I, the statistical analysis demonstrated that miR-125b expression was significantly associated with clinical stage $(\mathrm{P}=0.043)$ and alcohol history $(\mathrm{P}=0.010)$. However, there were no statistically significant associations between miR-125b expression and other clinicopathological features $(\mathrm{P}>0.05)$.

miR-125b decreases cell growth, migration and invasion in AMC-HN-8 cells. The CCK8 assay was performed to investigate the roles of miR-125b on cell growth. As presented in Fig. 2, miR-125b significantly decreased cell growth in AMC-HN-8 cells compared with the $\mathrm{NC}(\mathrm{P}<0.05)$. The inhibition rate of miR-125b in AMC-HN-8 cells was $26.51 \pm 3.5 \%$.

Transwell chambers were used to investigate the roles of miR-125b in cellular migration and invasion. As presented in Fig. 2B, miR-125b significantly inhibited AMC-HN-8 cell migration and invasion compared with the $\mathrm{NC}(\mathrm{P}<0.05)$. The results revealed that miR-125b serves a suppressive role in LSCC cell motility.

STAT3 is a direct target gene of miR-125b in vitro. To investigate the target genes of miR-125b, public databases (miRanda and TargetScan) were used. STAT3 was predicted to be a potential target of miR-125b (Fig. 3A). Subsequently, RT-qPCR and western blot analysis were performed to investigate the regulation of miR-125b on STAT3 expression at the mRNA and protein level in LSCC cells. As presented in Fig. 3B and C, STAT3 was significantly downregulated in AMC-HN-8 cells transfected with miR-125b compared with cells transfected with the $\mathrm{NC}(\mathrm{P}<0.05)$. Dual-luciferase reporter assays were also performed to determine whether STAT3 was a direct target gene of miR-125b. As presented in Fig. 3D, luciferase activity was significantly downregulated in the miR-125b mimics and pGL3-STAT3-3'UTR-Wt group, whereas there was no statistical difference in the miR-125b mimics and pGL3-STAT3-3'UTR-Mut group, compared with the respective NC groups. These results indicated that STAT3 was a direct gene of miR-125b in vitro. 


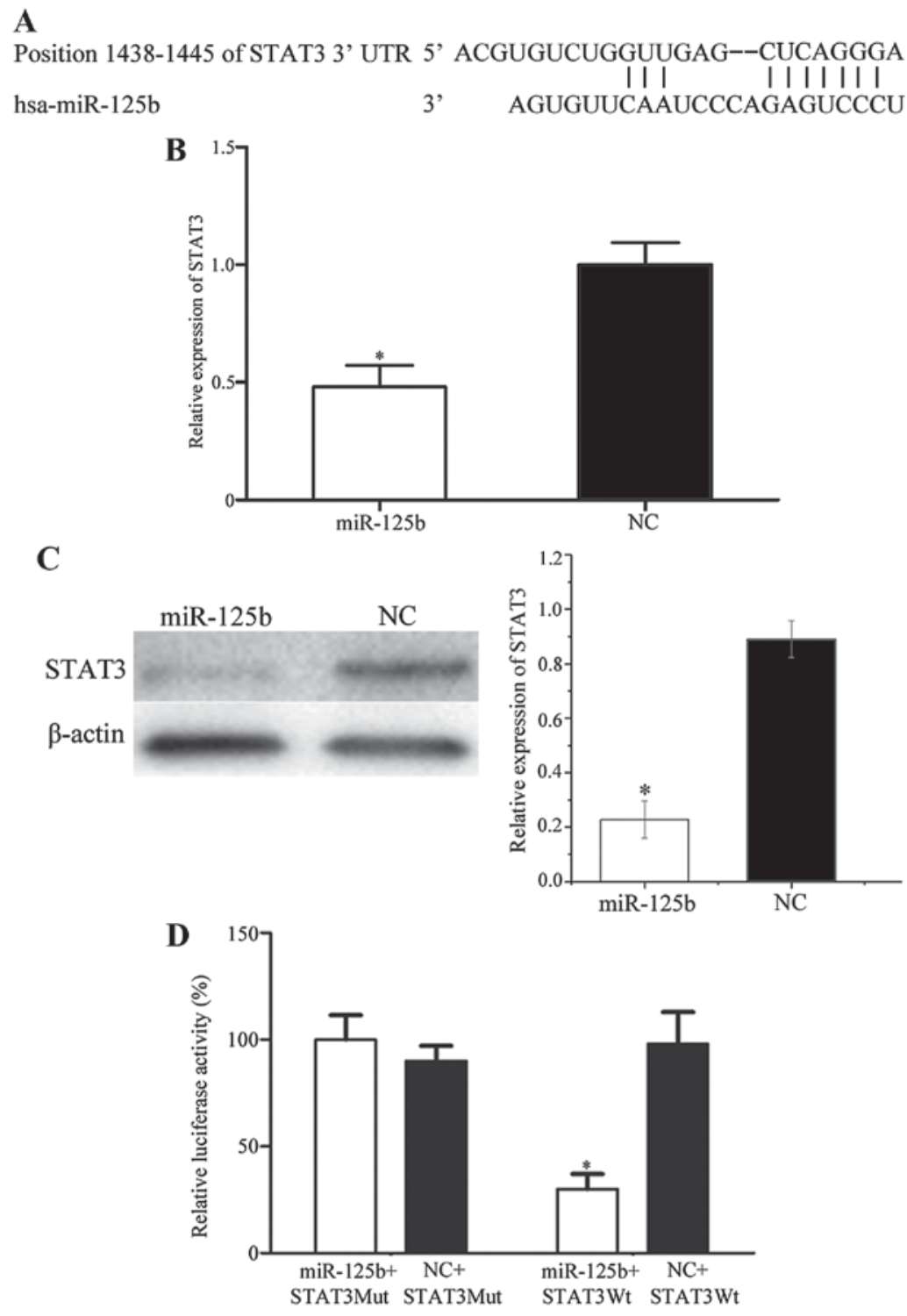

Figure 3. STAT3 is a direct target gene of miR-125b in vitro. (A) TargetScan and miRanda assessment demonstrated that STAT3 contained an miR-125b seed match at position 1438-1445 of the STAT3 3'-UTR. (B) Reverse transcription-quantitative polymerase chain reaction and (C) western blot analysis revealed that STAT3 was downregulated at the mRNA and protein levels, respectively, in AMC-HN-8 cells following transfection with miR-125b. (D) miR-125b inhibited the pGL3-STAT3-3'UTR-Wt luciferase activity; however, not the pGL3-STAT3-3'UTR-Mut luciferase activity in AMC-HN-8 cells. " $\mathrm{P}<0.05$ vs. the respective NC-transfected cells. STAT3, signal transducer and activator of transcription 3; miR, microRNA; UTR, untranslated region; Wt, wild-type; Mut, mutated; NC, negative control.

\section{Discussion}

miR-125 has two subtypes, miR-125a and miR-125b. miR-125b is encoded by the miR-125b-1 and miR-125b-2 genes, which are mapped to $11 \mathrm{q} 24.1$ and $21 \mathrm{q} 21.1$, respectively. However, miR-125b-1 and miR-125b-2 precursors are processed to form the same mature miRNA, miR-125b (22). miR-125b has been observed to be downregulated in various types of cancer, including oral cancer (23), bladder cancer (18), liver cancer (19), osteosarcoma (20) and endometrial cancer (24). Previous studies have also demonstrated that miR-125b was upregulated in a number of types of cancer, including prostate cancer (25), glioblastoma (26) and pediatric acute promyelocytic leukemia (27). However, there are no studies investigating the expression of miR-125b in LSCC. In the present study, it was observed that miR-125b was downregulated in LSCC tissue samples and cell lines. The statistical analysis also demonstrated that the expression level of miR-125b was associated with the clinical stage and alcohol history of patients with LSCC. The results suggested that miR-125b may serve important roles in LSCC.

Currently, the majority of studies have demonstrated that miR-125b functions as a tumor suppressor. For example, in bladder cancer, miR-125b inhibited cell proliferation and motility, and enhancedcellapoptosisbyregulating theexpression of nicotinamide-adenine dinucleotide-dependent protein deacetylase sirtuin-7 and matrix metalloproteinase-13 $(22,28)$. Furthermore, miR-125b decreased bladder cancer cell colony formation efficiency in vitro and the development of tumors in nude mice by targeting transcription factor E2F3 (18). In osteosarcoma, Liu et al (20) reported that miR-125b suppressed cell proliferation and migration via inhibition of 
STAT3. In endometrial cancer, miR-125b targeted receptor tyrosine-protein kinase erbB-2 to inhibit cell invasion (24). In human liver cancer, miR-125b was demonstrated to inhibit cell proliferation, migration and invasion by targeting LIN28B2 (19). Upregulation of miR-125b increased human hepatocellular carcinoma (HCC) cell sensitivity to 5-FU by regulating the expression of hexokinase II (29). However, miR-125b has also been verified to be an oncogene. In prostate cancer, miR-125b enhanced prostatic xenograft tumors proliferation through downregulation of p53 and Bcl-2-binding component 3 (30). In glioblastoma, Wu et al (26) verified that miR-125b was upregulated and significantly associated with poor prognosis. miR-125b functioned as an oncogene by suppressing cellular apoptosis and enhancing cellular proliferation. These opposing studies indicated that the functions of miR-125b in cancers are tissue-type dependent. In the present study, miR-125b was demonstrated to inhibit LSCC cell proliferation, migration and invasion. The present study expanded the expression and functions of miR-125b in cancer.

Identification of miR-125b target genes is essential for understanding its functions in LSCC carcinogenesis and cancer development. It is also important for investigating novel targeted therapies of LSCC. In the present study, an important molecular association between miR-125b and STAT3 was verified. The STAT family consists of seven members (STAT1, STAT2, STAT3, STAT4, STAT5a, STAT5b and STAT6) and STAT3 is a central transcription factor in the STAT family (31). In 1994, STAT3 was first verified to be an interleukin-6-activated acute-phase response factor (32). Multiple studies demonstrated that STAT3 serves essential roles in a variety of human cancer types, including LSCC (33-35). STAT3 serves important roles in mediating a number of oncogenic signaling pathways, including epidermal growth factor receptor signaling and Janus kinase (JAK)/STAT signaling pathways, and contributes to tumor physiological and pathological processes, including growth, survival, resistance to apoptosis, cell-cycle progression, angiogenesis and metastasis (36-38). Inhibition of STAT3 by pharmacological agents and genetic interference, suppressed cell growth, metastasis, enhanced apoptosis and decreased carcinogenesis $(39,40)$. These studies suggested that STAT3 may be a therapeutic target in the treatment of LSCC.

STAT3 has also been observed to be regulated by multiple miRNAs in a number of kinds of cancer. In HCC, miR-637 suppressed cell proliferation and enhanced cellular apoptosis through downregulation of STAT3 expression(41).miR-124 also inhibited HCC cell growth by directly targeting STAT3 (42). In pancreatic cancer, miR-130b decreased cell growth and invasion via inhibition of STAT3 (43). In gastric cancer, miR-874 targeted the STAT3/vascular endothelial growth factor A signaling pathway and functioned as a tumor suppressor (44). miR-375 was involved in helicobacter pylori-induced gastric tumorigenesis by inhibiting the activity of JAK2/STAT3 signaling (45). However, there are no studies about the regulation of STAT3 by miRNA in LSCC. In the present study, upregulation of miR-125b in LSCC revealed that miR-125b decreases cell growth and motility through regulation of STAT3. These studies suggested that miR-125b/STAT3-based targeted therapy may be a novel treatment for LSCC.

In conclusion, to the best of our knowledge, this was the first study to demonstrate that miR-125b was downregulated in LSCC, and associated with clinical stage and alcohol history. In addition, it was also demonstrated that miR-125b decreases cell growth, migration and invasion by directly targeting STAT3 in LSCC. The results revealed that the expression and function of miR-125b and its target gene STAT3 in LSCC, may aid in understanding the molecular mechanism of tumorigenesis and development, as well as providing a theoretical basis to investigate miR-125b as a further treatment target in LSCC.

\section{References}

1. Sun X, Song Y, Tai X, Liu B and Ji W: MicroRNA expression and its detection in human supraglottic laryngeal squamous cell carcinoma. Biomed Rep 1: 743-746, 2013.

2. Siegel RL, Miller KD and Jemal A: Cancer statistics, 2015. CA Cancer J Clin 65: 5-29, 2015.

3. Siegel R, Naishadham D and Jemal A: Cancer statistics, 2013. CA Cancer J Clin 63: 11-30, 2013.

4. Luo J, Wu J, Li Z, Qin H, Wang B, Wong TS, Yang W, Fu QL and Lei W: miR-375 suppresses IGF1R expression and contributes to inhibition of cell progression in laryngeal squamous cell carcinoma. Biomed Res Int 2014: 374598, 2014.

5. Guo Y, Fu W, Chen H, Shang C and Zhong M: miR-24 functions as a tumor suppressor in Hep2 laryngeal carcinoma cells partly through down-regulation of the S100A8 protein. Oncol Rep 27: 1097-1103, 2012

6. Cosetti M, Yu GP and Schantz SP: Five-year survival rates and time trends of laryngeal cancer in the US population. Arch Otolaryngol Head Neck Surg 134: 370-379, 2008.

7. Wang W, Lin P, Han C, Cai W, Zhao X and Sun B: Vasculogenic mimicry contributes to lymph node metastasis of laryngeal squamous cell carcinoma. J Exp Clin Cancer Res 29: 60, 2010.

8. Bartel DP: MicroRNAs: Genomics, biogenesis, mechanism, and function. Cell 116: 281-297, 2004.

9. Ying SY, Chang DC, Miller JD and Lin SL: The microRNA: Overview of the RNA gene that modulates gene functions. Methods Mol Biol 342: 1-18, 2006.

10. Maroney PA, Yu Y and Nilsen TW: MicroRNAs, mRNAs, and translation. Cold Spring Harb Symp Quant Biol 71: 531-535, 2006.

11. Zhao Y and Srivastava D: A developmental view of microRNA function. Trends Biochem Sci 32: 189-197, 2007.

12. Yates LA, Norbury CJ and Gilbert RJ: The long and short of microRNA. Cell 153: 516-519, 2013.

13. Tahara H, Kay MA, Yasui $W$ and Tahara E: MicroRNAs in cancer: The 22nd Hiroshima cancer Seminar/the 4th Japanese Association for RNA Interference Joint International Symposium, 30 August 2012, Grand Prince Hotel Hiroshima. Jpn J Clin Oncol 43: 579-582, 2013.

14. Karatas OF, Yuceturk B, Suer I, Yilmaz M, Cansiz H, Solak M, Ittmann M and Ozen M: Role of miR-145 in human laryngeal squamous cell carcinoma. Head Neck 38: 260-266, 2016.

15. Tian L, Zhang J, Ge J, Xiao H, Lu J, Fu S, Liu M and Sun Y: MicroRNA-205 suppresses proliferation and promotes apoptosis in laryngeal squamous cell carcinoma. Med Oncol 31: 785, 2014.

16. Tian Y, Fu S, Qiu GB, Xu ZM, Liu N, Zhang XW, Chen S, Wang Y, Sun KL and Fu WN: MicroRNA-27a promotes proliferation and suppresses apoptosis by targeting PLK2 in laryngeal carcinoma. BMC Cancer 14: 678, 2014.

17. Wu D, Zhou Y, Pan H, Zhou J, Fan Y and Qu P: microRNA-99a inhibiting cell proliferation, migration and invasion by targeting fibroblast growth factor receptor 3 in bladder cancer. Oncol Lett 7: 1219-1224, 2014.

18. Huang L, Luo J, Cai Q, Pan Q, Zeng H, Guo Z, Dong W, Huang J and Lin T: MicroRNA-125b suppresses the development of bladder cancer by targeting E2F3. Int J Cancer 128: 1758-1769, 2011.

19. Liang L, Wong CM, Ying Q, Fan DN, Huang S, Ding J, Yao J, Yan M, Li J, Yao M, et al: MicroRNA-125b suppressesed human liver cancer cell proliferation and metastasis by directly targeting oncogene LIN28B2. Hepatology 52: 1731-1740, 2010.

20. Liu LH, Li H, Li JP, Zhong H, Zhang HC, Chen J and Xiao T: miR-125b suppresses the proliferation and migration of osteosarcoma cells through down-regulation of STAT3. Biochem Biophys Res Commun 416: 31-38, 2011. 
21. Livak KJ and Schmittgen TD: Analysis of relative gene expression data using real-time quantitative PCR and the 2(-Delta Delta C(T)) Method. Methods 25: 402-408, 2001.

22. Wu D, Ding J, Wang L, Pan H, Zhou Z, Zhou J and Qu P: microRNA-125b inhibits cell migration and invasion by targeting matrix metallopeptidase 13 in bladder cancer. Oncol Lett 5: 829-834, 2013

23. Henson BJ, Bhattacharjee S, O'Dee DM, Feingold E and Gollin SM: Decreased expression of miR-125b and miR-100 in oral cancer cells contributes to malignancy. Genes Chromosomes Cancer 48: 569-582, 2009.

24. Shang C, Lu YM and Meng LR: MicroRNA-125b down-regulation mediates endometrial cancer invasion by targeting ERBB2. Med Sci Monit 18: BR149-BR155, 2012.

25. Amir S, Ma AH, Shi XB, Xue L, Kung HJ and Devere White RW: Oncomir miR-125b suppresses p14(ARF) to modulate $\mathrm{p} 53$-dependent and $\mathrm{p} 53$-independent apoptosis in prostate cancer. PLoS One 8: e61064, 2013.

26. Wu N, Lin X, Zhao X, Zheng L, Xiao L, Liu J, Ge L and Cao S: MiR-125b acts as an oncogene in glioblastoma cells and inhibits cell apoptosis through p53 and p38MAPK-independent pathways. Br J Cancer 109: 2853-2863, 2013.

27. Zhang $\mathrm{H}$, Luo XQ, Feng DD, Zhang XJ, Wu J, Zheng YS, Chen X, Xu L and Chen YQ: Upregulation of microRNA-125b contributes to leukemogenesis and increases drug resistance in pediatric acute promyelocytic leukemia. Mol Cancer 10: 108, 2011.

28. Han Y, Liu Y, Zhang H, Wang T, Diao R, Jiang Z, Gui Y and Cai Z: Hsa-miR-125b suppresses bladder cancer development by down-regulating oncogene SIRT7 and oncogenic long non-coding RNA MALAT1. FEBS Lett 587: 3875-3882, 2013.

29. Jiang JX, Gao S, Pan YZ, Yu C and Sun CY: Overexpression of microRNA-125b sensitizes human hepatocellular carcinoma cells to 5-fluorouracil through inhibition of glycolysis by targeting hexokinase II. Mol Med Rep 10: 995-1002, 2014.

30. Shi XB, Xue L, Ma AH, Tepper CG, Kung HJ and White RW: miR-125b promotes growth of prostate cancer xenograft tumor through targeting pro-apoptotic genes. Prostate 71: 538-549, 2011.

31. Hennighausen L and Robinson GW: Interpretation of cytokine signaling through the transcription factors STAT5A and STAT5B. Genes Dev 22: 711-721, 2008.

32. Lütticken C, Wegenka UM, Yuan J, Buschmann J, Schindler C, Ziemiecki A, Harpur AG, Wilks AF, Yasukawa K, Taga T, et al: Association of transcription factor APRF and protein kinase Jak1 with the interleukin-6 signal transducer gp130. Science 263: 89-92, 1994.

33. Dai L, Liu T, Zhou X, Wei Q, Li Y, Cui C and Li M: Expression and significance of phosphated signal transducer and activator of transcription 3 and 553 protein in laryngeal squamous cell carcinoma. Lin Chung Er Bi Yan Hou Tou Jing Wai Ke Za Zhi 27: 991-994, 2013 (In Chinese).

34. Zhao H, Wamg Y and He X: Expression of p-STAT3 in laryngeal squamous carcinoma and its correlation with PTEN. Lin Chung Er Bi Yan Hou Tou Jing Wai Ke Za Zhi 27: 981-985, 2013 (In Chinese).
35. Wang L, Duan X, Tang X, Shao Y, Zhao R, Qian X and Gao X: Clinical significance of Stat 3 and Cyclin D1 expression in laryngeal squamous cell carcinoma. Lin Chung Er Bi Yan Hou Tou Jing Wai Ke Za Zhi 25: 966-969, 2011 (In Chinese).

36. Zhong Z, Wen Z and Darnell JE Jr: Stat3: A STAT family member activated by tyrosine phosphorylation in response to epidermal growth factor and interleukin-6. Science 264: 95-98, 1994.

37. Bromberg J and Darnell JE Jr: The role of STATs in transcriptional control and their impact on cellular function. Oncogene 19: 2468-2473, 2000.

38. Kamran MZ, Patil P and Gude RP: Role of STAT3 in cancer metastasis and translational advances. Biomed Res Int 2013 421821, 2013

39. Xiong A, Yang Z, Shen Y, Zhou J and Shen Q: Transcription factor STAT3 as a novel molecular target for cancer prevention. Cancers (Basel) 6: 926-957, 2014.

40. Siveen KS, Sikka S, Surana R, Dai X, Zhang J, Kumar AP, Tan BK, Sethi G and Bishayee A: Targeting the STAT3 signaling pathway in cancer: Role of synthetic and natural inhibitors. Biochim Biophys Acta 1845: 136-154, 2014.

41. Zhang JF, He ML, Fu WM, Wang H, Chen LZ, Zhu X, Chen Y, Xie D, Lai P, Chen G, et al: Primate-specific microRNA-637 inhibits tumorigenesis in hepatocellular carcinoma by disrupting signal transducer and activator of transcription 3 signaling. Hepatology 54: 2137-2148, 2011.

42. Lu Y, Yue X, Cui Y, Zhang J and Wang K: MicroRNA-124 suppresses growth of human hepatocellular carcinoma by targeting STAT3. Biochem Biophys Res Commun 441: 873-879, 2013.

43. Zhao G, Zhang JG, Shi Y, Qin Q, Liu Y, Wang B, Tian K, Deng SC, Li X, Zhu S, et al: MiR-130b is a prognostic marker and inhibits cell proliferation and invasion in pancreatic cancer through targeting STAT3. PLoS One 8: e73803, 2013.

44. Zhang X, Tang J, Zhi X, Xie K, Wang W, Li Z, Zhu Y, Yang L, $\mathrm{Xu} \mathrm{H}$ and $\mathrm{Xu} \mathrm{Z}$ : miR-874 functions as a tumor suppressor by inhibiting angiogenesis through STAT3/VEGF-A pathway in gastric cancer. Oncotarget 6: 1605-1617, 2015.

45. Miao L, Liu K, Xie M, Xing Y and Xi T: miR-375 inhibits Helicobacter pylori-induced gastric carcinogenesis by blocking JAK2-STAT3 signaling. Cancer Immunol Immunother 63: 699-711, 2014. 